\title{
Glucagon-like Peptide-1 Receptor Agonists and Cardioprotective Benefit in Patients With Type 2 Diabetes Without Baseline Metformin: An Update Meta-analysis
}

\author{
Augusto Lavalle Cobo ( $\sim$ augustolavallecobo@hotmail.com ) \\ Sanatorio Finochietto https://orcid.org/0000-0002-1257-9211 \\ Walter Masson \\ Hospital Italiano de Buenos Aires \\ Martin Lobo \\ Hospital Militar Campo de Mayo \\ Gerardo Masson \\ Instituto Cardiovascular San Isidro-Sanatorio Las Lomas \\ Graciela Molinero \\ Council of Epidemiology and Cardiovascular Prevention, Argentinian Society of Cardiology
}

\section{Original investigation}

Keywords: Diabetes, GLP-1Ras, cardiovascular outcomes, metformin

Posted Date: June 30th, 2021

DOI: https://doi.org/10.21203/rs.3.rs-664920/v1

License: (c) (i) This work is licensed under a Creative Commons Attribution 4.0 International License. Read Full License 


\section{Abstract}

Background: Sodium Glucose Co-transporter 2 inhibitors and glucagon-like peptide-1 receptor agonists (GLP-1RAs) were associated with a reduction in cardiovascular events in cardiovascular outcomes trials (CVOTs) in type 2 diabetes. Most of the patients included in these trials received metformin as background therapy. The purpose of this study was to evaluate the effect of glucagon-like peptide-1 receptor agonists on major cardiovascular events (MACE) in metformin-naïve patients with type 2 diabetes.

Methods: A meta-analysis was performed of randomized controlled clinical trials of GLP-1RAs on type 2 diabetes populations, after searching the PubMed/MEDLINE, Embase, Scielo, Google Scholar and Cochrane Controlled Trials databases. The primary endpoint was MACE. The secondary endpoints were cardiovascular death and all-cause mortality. A meta-analysis of time-to-event outcomes was performed.

Results: Six eligible trials, including 10419 patients, were identified and considered eligible for the analyses. GLP-1RAs were associated with a significant reduction in MACE incidence (HR: $0.87,95 \%$ confidence interval: $\left.0.80-0.94 ; I^{2}: 0 \%\right)$. The analysis of the secondary endpoints showed a non-significant reduction in all-cause mortality (HR: $0.86,95 \%$ confidence interval: 0.73-1.00 $\mathrm{I}^{2}: 0 \%$ ) and cardiovascular mortality (HR: 0.81, 95\% confidence interval: $0.63-1.05 ; \mathrm{I}^{2}: 0 \%$ ).

Conclusions: In this meta-analysis, GLP-1RAs reduced the incidence of MACE in patients with type 2 diabetes without metformin at baseline, without significant reduction in all-cause mortality and cardiovascular mortality. These results support the fact that benefit in cardiovascular outcomes is independent of metformin use when GLP-1Ras are administered.

\section{Introduction}

People with type 2 diabetes (T2D) are at increased risk for cardiovascular disease (CVD) and have worse outcomes after surviving a cardiovascular event [1-2]. Prevalence of cardiovascular complications in people with T2D is variable. Furthermore, CVD risk is increasing over time. In ZODIAC-13 study, a longitudinal study including 881 patients with T2D over 10 years, the hazard ratio (HR) for death due to CVD was constantly increasing each year [3]. In a recent crosssectional study of 9823 adults with T2D attending a primary or specialist showed that approximately one in three adults had established CVD [4]. Furthermore, Cebrián Cuenca et al., reported in 373.185 patients with T2D from a Mediterranean region in Spain that 53\% of them were classified as very high cardiovascular risk [5]. Regarding antidiabetic treatment new emerging classes of drugs, sodium-glucose cotransporter-2 (SGLT-2) inhibitors and glucagon-like peptide-1 receptor agonists (GLP-1RAs) have been shown to reduce cardiovascular events in patients with T2D and a high cardiovascular risk or established cardiovascular disease [6-14]. Recent 2019 guidelines by the European Society of Cardiology (ESC)/European Association for the study of Diabetes (EASD) on diabetes, prediabetes, and cardiovascular disease recommend SGLT-2 or GLP-1RAs inhibitors as first-line therapies in patients with established cardiovascular disease or high / very high cardiovascular risk. [15]. These recommendations were acquired from data from cardiovascular outcome trials (CVOTs) in which enrolled patients received mostly metformin as background therapy. The question whether the cardiovascular benefits observed in these trials are similar in patients with or without metformin arises from the observation of the contrast between the recommendations of the guidelines and the limited information on subjects who had not received metformin.

Recently subgroups analyses of trials with some of these drugs were published reporting cardiovascular benefits in patients who were not receiving metformin [16-18]. Two previous meta-analysis, using data from a small number of trials, described the reduction of MACE in patients with T2D who received GLP-1RAs regardless of the background use of metformin. [19-20] In this study we included the last three studies published on this topic, and evaluate other endpoints 
not previously analyzed such as total and cardiovascular mortality. Therefore, the objective of the present meta-analysis was to evaluate the effect of GLP-1RAs on MACE and other outcomes regardless of background use of metformin.

\section{Material And Methods}

\section{Data extraction and quality assessment}

This meta-analysis was performed according to the Preferred Reporting Items for Systematic Reviews and Meta-Analyses guidelines for reporting systematic reviews [21].

A literature search was performed that identified clinical trials of GLP-1RAs published between January 2010 and May 2021. Two independent reviewers searched the electronic PubMed/MEDLINE, Embase, Scielo, Google Scholar and Cochrane Controlled Trials databases using the terms "liraglutide", "albiglutide", "exenatide", "lixisenatide", "semaglutide"," dulaglutide", and "GLP-1RAs", alone or combined with "cardiovascular disease", "major cardiovascular events (MACE)", "mortality", "cardiovascular mortality", "stroke", or "myocardial infarction".

All the analyzed studies meet the following inclusion criteria: (1) comparisons of efficacy for GLP-1RAs vs. placebo; (2) follow-up duration $\geq 1$ year; (3) randomized clinical trials; (4) reporting incidence of MACE; and (5) reporting data from patients without metformin at baseline.

The primary endpoint of the study was MACE incidence (composite of myocardial infarction, stroke, and cardiac death). Cardiovascular mortality and all-cause of mortality were evaluated as secondary endpoints. This meta-analysis was registered in PROSPERO.

The Cochrane risk-of-bias tool for randomized trials (RoB 2) was used to assess the potential risk of bias of each included trial [22]. RoB 2 is structured into five distinct domains: bias arising from the randomization process, bias due to deviations from intended interventions, bias due to missing outcome data, bias in the outcome measurement and bias in selection of the reported result. Each domain was rated as "low risk of bias," "high risk of bias" or "some concerns".

\section{Statistical analysis}

Since the number of events in the subgroups with or without metformin were not reported in most studies, a meta-analysis of time-to-event outcomes was performed [23]. Hazard ratios (HRs) and 95\% confidence intervals (Cls) were abstracted from each individual study and standard error were calculated. All study-specific estimates were combined using an inverse variance method for pooling. The logarithm of the HRs and their standard errors were used. The summary effect of statin therapy on the endpoints were calculated. Measures of effect size were expressed as HRs, and the $\mathrm{I}^{2}$ statistic was calculated to quantify between-studies heterogeneity and inconsistency. Because the $\mathrm{I}^{2}$ was low, a fixed-effects model was chosen. Statistical analyses were performed using the R software for statistical computing version 3.5.1 with additional specific packages [24]. The level of statistical significance was set at a 2-tailed alpha of .05.

\section{Sensitivity analyses}

The sensitivity analysis is carried out by replicating the results of the meta-analysis, excluding at each step one of the studies included in the review. The robustness of the analysis is indicated by the similarity of the results obtained in the direction and magnitude of the effect and the statistical significance. A sensitivity analysis for the primary endpoint was performed.

\section{Analysis of publication bias}

A funnel plot using the standard error (SE) for log HR was created. In addition, Egger's regression intercept tests were done. A p-value less than 0.1 was considered significant for the linear regression test.

Page 3/12 


\section{Results}

Six eligible trials ( 5 studies of subcutaneous GLP-1RAs and 1 with oral GLP-1RAs), including 10419 patients, were identified and considered eligible for the analyses. A total of 5274 subjects were allocated to receive GLP-1RAs while 5145 subjects were allocated to the respective control arms. A flow diagram of the study's screening process has been shown in Fig. 1.

The total of studies evaluated were randomized clinical trials. Overall, the risk of bias was low in all the six studies. The quality of the studies evaluated can be seen in Fig. 2.

All studies included patients with T2D. Four studies included more than $80 \%$ of patients with a history of cardiovascular disease. Five studies included patients with high cardiovascular risk according to a set of associated cardiovascular risk factors. In addition, two studies considered chronic renal disease as an inclusion criteria. All trials reported MACE, but only four studies reported all-cause of death and three trials cardiovascular death. Data from the semaglutide studies (SUSTAIN6 and PIONEER) were reported, and consequently included in our analysis jointly. Median follow-up duration ranged from 1.4 to 5.4 years. The characteristics of the studies included in the analysis can be seen in Table 1 .

Table 1

Characteristics of the selected randomized controlled trials for analysis.

\begin{tabular}{|c|c|c|c|c|c|c|}
\hline & EXSCEL $^{11}$ & HARMONY12 & LEADER $^{17}$ & REWIND ${ }^{18}$ & SUSTAIN $6{ }^{26}$ & PIONEER $6^{26}$ \\
\hline Intervention & Exenatide & Albiglutide & Liraglutide & Dulaglutide & Semaglutide & Semaglutide \\
\hline $\begin{array}{l}\text { Patients } \\
\text { included }\end{array}$ & $\mathrm{T} 2 \mathrm{D}$ & $\begin{array}{l}\text { T2D and } \geq 40 \\
\text { years old with } \\
\text { history of } \\
\text { cardiovascular } \\
\text { disease }\end{array}$ & $\begin{array}{l}\text { T2D and high } \\
\text { cardiovascular } \\
\text { risk }\end{array}$ & $\begin{array}{l}\text { T2D with } \\
\text { history of } \\
\text { cardiovascular } \\
\text { disease or } \\
\text { high } \\
\text { cardiovascular } \\
\text { risk }\end{array}$ & $\begin{array}{l}\text { T2D and high } \\
\text { cardiovascular } \\
\text { risk }\end{array}$ & $\begin{array}{l}\mathrm{T} 2 \mathrm{D} \text { and high } \\
\text { cardiovascular } \\
\text { risk }\end{array}$ \\
\hline $\begin{array}{l}\text { Follow-up, } \\
\text { years }\end{array}$ & 3.2 & 1.6 & 3.8 & 5.4 & 2.1 & 1.4 \\
\hline $\begin{array}{l}\text { Total patients, } \\
\mathrm{n}\end{array}$ & 14752 & 9463 & 9340 & 9901 & 3297 & 3183 \\
\hline $\begin{array}{l}\text { Metformin- } \\
\text { naïve patients, } \\
n\end{array}$ & 2261 & 2495 & 2196 & 1864 & 919 & 680 \\
\hline $\begin{array}{l}\text { Mean age, } \\
\text { years }\end{array}$ & 62 & 64.1 & 64.3 & 66.2 & 64.6 & 66 \\
\hline Female, \% & 38 & 30.6 & 35.7 & 46.3 & 39.3 & 31.6 \\
\hline $\begin{array}{l}\text { Cardiovascular } \\
\text { disease, \% }\end{array}$ & 73.1 & 100 & 81.4 & 31.4 & 83 & 84.7 \\
\hline
\end{tabular}

The present meta-analysis revealed that GLP-1RAs drugs were associated with a significant reduction in MACE (HR: 0.87, $\left.95 \% \mathrm{Cl}: 0.80-0.94 ; 1^{2}: 0 \%\right)$. The analysis of the secondary endpoint showed that GLP-1RAs were associated with a nonsignificant reduction in all-cause mortality (HR: $0.86,95 \% \mathrm{Cl}: 0.73-1.00 ; \mathrm{I}^{2}$ : $0 \%$ ) and cardiovascular mortality (HR: $0.81,95 \%$ Cl: $\left.0.63-1.05 ; I^{2}: 0 \%\right)$ The graphic representation of the effect of GLP-1RAs on primary and secondary end-point can be seen in Fig. 3.

The funnel plot in Fig. 4 and analytical evaluation do not suggest publication bias (Egger's asymmetry test, $p=0.19)$. The sensitivity analysis showed the same directionality of results when studies were excluded one by one (Fig. 5), 


\section{Discussion}

In this meta-analysis, in which only patients without metformin at baseline were included, GLP-1RAs (compared with placebo) were associated with a significant reduction in MACE incidence with a trending forward reduction in all-cause mortality. Metformin has been first line therapy recommended for treatment of patients with T2D for a long time. Results from CVOTs where GLP-1RAs an SGLT2 inhibitors added to standard therapy all have found non-inferiority with many finding superiority respect to placebo [6-14] led to a rethinking of the paradigm of metformin as the first drug choice, and GLP-1RAs arise in some guidelines as the first line therapy in patients with cardiovascular disease o high cardiovascular risk $[15,25]$.

This discussion is not focused on the glucose lowering effect of metformin or GLP-1RAs but on the impact in terms on reduction in cardiovascular events. Regarding this issue, the supporting data for the cardiovascular benefit of metformin is drawn for the most part from a sub study of the UKPDS trial; all patients included were overweight and control group was usual care (diet, with sulfonylurea or insulin). This study had a small sample size and was not powered to prove cardiovascular benefit [27]. Currently there is no published data from placebo controlled cardiovascular outcomes trials with metformin in patients with T2D. There have been several meta-analyses to investigate the effects of metformin on cardiovascular events, but data have not been particularly conclusive [28-31].

Cardiovascular benefit observed with GLP-1RAs use in CVOTs is overwhelming. However, most of the patients evaluated in these trials received metformin at baseline. An exploratory subgroup analysis was recently performed in some of these trials, reporting that the reduction in MACE was independent of background metformin therapy. Two different metaanalysis including data from 3 GLP-1RAs CVOTs evidenced that GLP1-RAs were associated with a significant reduction in the risk of MACE of $20 \%$ and $23 \%$, respectively [19-20]. None of the mentioned meta-analyses reported other outcomes than MACE. In this context, the results of this meta-analysis become relevant, since it includes a great number of patients from six different trials.

GLP1-RAs promotes glycemic reduction for the treatment of T2D by glucose-dependent control of insulin and glucagon secretion which results in a low risk of hypoglycemia. GLP1-RAs also decelerate gastric emptying, lower circulating lipoproteins, inflammation, increased satiety and decreased body weight [31]. Furthermore, GLP1-RAs are associated with a variety of positive cardiovascular and renal effects beyond glycemic control. GLP-1RAs improves blood pressure, vascular tone and cardioprotection against myocardial ischemia/stunning [32]. Although improving glycemic control is associated with a reduction of microvascular complications in people with T2D, [33] its impact in reduction of macrovascular complications is not so categorical. Despite a reduction in the incidence of myocardial infarction and death due to an early glycemic control reported in UKPDS, trials like VADT, ADVANCE and ACCORD failed to demonstrate cardiovascular benefit with an intensive glucose control strategy. [34-36]. From the above it follows that cardiovascular benefit exceeds glycemic control, the use of GLP-1RAs could maintain the positive cardiovascular profile regardless use of metformin.

The reduction in MACE observed in this meta-analysis in patients receiving GLP-1RAs without metformin follows the same line as CVOTs. Metformin increases glucagon-like peptide-1 secretion [37]. In patients receiving GLP1-RAs this effect is avoided. This meta-analysis cannot answer the question about what is the mechanism of GLP-1AR that leads to a reduction in MACE, but it may suggest that this benefit does not depend on the use of metformin at baseline.

A meta-analysis of CVOTs, comparing GLP-1RAs and placebo, comprising 56004 patients showed not only a reduction in MACE but also a significant reduction in all-cause mortality and in cardiovascular death [38]. In the present meta-analysis, which only includes patients without baseline metformin, no significant reduction in the mentioned results has been observed. The cause could be the small number of patients included in our study. The total of patients included in our meta-analysis represents $20 \%$ of the one mentioned above. The fact that only four studies reported all-cause of death and three trials cardiovascular death, could reduce even more the power to detect a difference between these two groups of 
patients. Since metformin trials didn't show a reduction in these endpoints, we don't think that this is the reason why we didn't observe the benefit described before.

This meta-analysis presents several limitations. First, limitations related with clinical heterogeneity (popular characteristics, different schemes of antihyperglycemic drugs, different follow-up). However, the sensitivity analysis showed the same directionality of the results. Second, the analysis included only trial-level data without having the individual data. Consequently, exploratory analysis of certain subgroups according to baseline characteristics could not be performed. Third, the characteristics of patients who were not treated with metformin at baseline may be not necessarily similar to those of the total populations of the included studies. Unfortunately, the characteristics of the subgroups of patients without metformin at baseline have not been published in all included studies. However, the characteristics of the total populations were similar. The reported body mass index ranged between 30.6 and $32.5 \mathrm{~kg} / \mathrm{m}^{2}$ and the baseline HbA1c level ranged between $7.3 \%$ and $8.7 \%$. Similarly, the use of statins ranged between $72.2 \%$ and $86.4 \%$ and the use of insulin ranged between $44.7 \%$ and $60.4 \%$. Finally, the number of studies reporting all cause mortality and cardiovascular mortality was small. Therefore, it is necessary to have larger studies to confirm or refute our findings.

In conclusion, in the present meta-analysis GLP-1RAs reduced the incidence of MACE in patients with T2D regardless use of metformin. These results support the fact that metformin would not be needed to obtain positive cardiovascular effects when this class of drugs are administered.

\section{Abbreviations}

T2D: Type 2 diabetes

CVD: Cardiovascular disease

HR: Hazard Ratio

SGLT-2: Sodium Glucose co-transporter 2

GLP-1Ras: Glucagon-like peptide-1 receptor agonists

EASD: European Association for the study of diabetes

ESC: European Society of Cardiology

CVOTs: Cardiovascular outcomes trials

MACE: Major adverse cardiovascular events

Cl: Confidence interval

SE: Standard error

\section{Declarations}

Ethics approval and consent to participate: Not applicable

Consent for publication: Not applicable

Availability of data and materials: Authors can confirm that all relevant data are included in the article and/or its supplementary information files. 
Competing interests: Augusto Lavalle Cobo has received honoraria from Novo Nordisk.

Funding: Journal submission was financially funded by Novo Nordisk. The authors take full responsibility for the content and conclusion stated in this manuscript. Novo Nordisk neither influenced the content of this publication nor was it involved in the study design, data collection, analysis, interpretation or review.

Authors' contributions: ALC was the main coordinator of the project and was responsible for the study design. ALC and WM drafted the manuscript of the present paper. ML was involved in the supervising of data collection and stratification. $M L$ and GM contributed to data assembly and analysis. GM contributed with manuscript revision. All authors contributed intellectually to this manuscript and have approved this final version.

Acknowledgements: Not applicable

Authors' information (optional): Not applicable

\section{References}

1. Buse JB, Ginsberg HN, Bakris GL, Clark NG, Costa F, Eckel R, et al. Primary prevention of cardiovascular diseases in people with diabetes mellitus: a scientific statement from the American heart association and the American diabetes association. Diabetes Care 2007 Jan; 30(1): 162-172.

2. https://doi.org/10.2337/dc07-9917.

3. International Diabetes Federation. Diabetes and cardiovascular disease.Brussels. International Diabetes Federation; 2016. pp. 1-144.

4. Van Hateren KJ, Landman GW, Kleefstra N, Logtenberg SJ, Groenier KH, Kamper AM, Houweling ST, Bilo HJ. The lipid profile and mortality risk in elderly type 2 diabetic patients: a 10-year follow-up study (ZODIAC-13). PLoS ONE. 2009;4:e8464. https://doi.org/10.1371/journal.pone.0008464.

5. Mosenzon O, Alguwaihes A, Arenas Leon JL, Bayram F, Darmon P, Davis T, et al. CAPTURE: a cross-sectional study of the contemporary (2019) prevalence of cardiovascular disease in adults with type 2 diabetes across 13 countries. Diabetologia 2020 Aug 25:1-485. https://doi.org/10.1007/s00125-020-05221-5.

6. Cebrián-Cuenca AM, Mata-Cases M, Franch-Nadal J, Mauricio D, Orozco-Beltrán D, Consuegra-Sánchez L. Half of patients with type 2 diabetes mellitus are at very high cardiovascular risk according to the ESC/EASD: data from a large Mediterranean population. Eur J Prev Cardiol. 2020 Nov 14. https://doi.org/10.1093/eurjpc/zwaa073.

7. Zinman B, Wanner C, Lachin JM, Fitchett D, Bluhmki E, Hantel S, et al. Empagliflozin, Cardiovascular Outcomes, and Mortality in Type 2 Diabetes N Engl J Med 2015;Nov 26;373(22):2117-28. https://doi.org/10.1056/NEJMoa1504720.

8. Neal B, Perkovic V, Mahaffey KW, de Zeeuw D, Flucher G, Erondu N, et al. Canagliflozin and Cardiovascular and Renal Events in Type 2 Diabetes. N Engl J Med 2017 Aug 17;377(7):644-657. https://doi.org/10.1056/NEJMoa1611925.

9. Wiviott S, Raz I, Bonaca MP, Mosenzon O, Kato E, Cahan A, et al. Dapagliflozin and Cardiovascular Outcomes in Type 2 Diabetes. N Engl J Med 2019 Jan 24;380(4):347-357. https://doi.org/10.1056/NEJMoa1812389.

10. Cannon CP, Pratley R, Dagogo-Jack S, Mancuso J, Huyck S, Masiukiewicz U, et al. Cardiovascular Outcomes with Ertugliflozin in Type 2 Diabetes. N Engl J Med. 2020;383:1425-35. https://doi.org/10.1056/NEJMoa2004967.

11. Marso SP, Daniels GH, Brown-Frandsen K, Kristensen P, Mann JFE, Nauck MA, et al. Liraglutide and Cardiovascular Outcomes in Type 2 Diabetes. N Engl J Med 2016 Jul 28;375(4):311 - 22. https://doi.org/10.1056/NEJMoa1603827.

12. Holman RR, Bethel MA, Mentz RJ, Thompson V, Lokhnygina, Buse JB, et al. Effects of Once-Weekly Exenatide on Cardiovascular Outcomes in Type 2 Diabetes. N Engl J Med. 2017 Sep 28;377(13):1228-1239.

https://doi.org/10.1056/NEJMoa1612917. 
13. Hernández AF, Green JB, Janmohamed S, D’Agostino RB, Granger CB, Jones NP, et al. Albiglutide and cardiovascular outcomes in patients with type 2 diabetes and cardiovascular disease (Harmony Outcomes): a double-blind, randomised placebo-controlled trial. Lancet. 2018 Oct 27;392(10157):1519-1529. https://doi.org/10.1016/S01406736(18)32261-X.

14. Gerstein HC, Colhoun HM, Dagenais GR, Diaz R, Lakshmanan M, Pais P, et al. Dulaglutide and cardiovascular outcomes in type 2 diabetes (REWIND): a double-blind, randomised placebo-controlled trial. Lancet. 2019 Jul 13;394(10193):121-130. https://doi.org/10.1016/S0140-6736(19)31149-3.

15. Marso SP, Bain SC, Consoli A, Eliaschewitz FG, Jódar E, Leiter LA, et al. Semaglutide and Cardiovascular Outcomes in Patients with Type 2 Diabetes. N Engl J Med. 2016;375:1834-44.

16. https://doi.org/10.1056/NEJMoa1607141.

17. Cosentino F, Grant PJ, Aboyans V, Bailey CJ, Ceriello A, Delgado V, et al. ESC Scientific Document Group. 2019 ESC Guidelines on diabetes, pre-diabetes, and cardiovascular diseases developed in collaboration with the EASD. Eur Heart J. 2020 Jan 7;41(2):255-323. https://doi.org/10.1093/eurheartj/ehz486.

18. Hüttner S, Zinman B, Fitchett D, Woo V, Mattheus M, Janista JT, et al. EMPA-REG OUTCOME: empagliflozin (EMPA) reduced the risk of cardiovascular (CV) outcomes and mortality irrespective of metformin (MET) use at baseline. Diabetologia. 2017;60(Suppl1):1-608.

19. Crowley M, McGuire D, Alexopoulos As, Jensen TJ, Rasmussen S, Saevereid H, et al. Effects of Liraglutide on Cardiovascular Outcomes in Type 2 Diabetes Patients With and Without Baseline Metformin Use: Post Hoc Analyses of the LEADER Trial. Diabetes Care 2020 Sep; 43(9): e108-e110. https://doi.org/10.2337/dc20-0437.

20. Ferrannini G, Gerstein HC, Colhoun HM, Dagenais R, Diaz R, Dyal L, et al. Cardio protection with dulaglutide is not depending on baseline therapy with metformin: a subgroup analysis of the REWIND trial. Diabetologia 2020 Aug 25:1485. https://doi.org/10.1007/s00125-020-05221-5.

21. Masson W, Lavalle Cobo A, Lobo M, Masson G, Graciela M. Novel antidiabetic drugs and risk of cardiovascular events in patients without baseline metformin use: a meta-analysis. Eur J Prev Cardiol. 2021. Mar 23;28(1):69-75. https://doi.org/10.1093/eurjpc/zwaa074.

22. Escobar C, Barrios V, Cosin J, Gamez Martinez JM, Huelmos Rodrigo Al, Ortiz Cortes, Carolina, et al. SGLT2 inhibitors and GLP1 agonist administered without metformin compared to other glucose-lowering drugs in patients with type 2 diabetes mellitus to prevent cardiovascular events: A systematic review. Diabet Med. 2021 Mar;38(3):e14502. https://doi.org/10.1111/dme.14502.

23. Liberati A, Altman DG, Tetzlaff J, et al. The PRISMA statement for reporting systematic reviews and metaanalyses of studies that evaluate healthcare interventions: explanation and elaboration. Br Med J. 2009;339:b2700. https://doi.org/10.1136/bmj.b2700.

24. Sterne JAC, Savovi J, Page MJ, Elbers RG, Blencowe NS, Boutronet I. al. RoB 2: a revised tool for assessing risk of bias in randomised trials. BMJ. 2019;366:14898. https://doi.org/10.1136/bmj.14898.

25. Tierney JF, Stewart LA, Ghersi D, Burdett S, Sydes MR. Practical methods for incorporating summary time-to-event data into meta-analysis. Trials. 2007 Jun 7;8:16. https://doi.org/10.1186/1745-6215-8-16.

26. Viechtbauer W. Conducting meta-analyses in R with the metaphor package. J Stat Softw. 2010;36:1-48. https://doi.org/10.18637/jss.v036.i03.

27. Pharmacologic Approaches to Glycemic Treatment. Standards of Medical Care in Diabetes-2021. American Diabetes Association. Diabetes Care. 2021 Jan;44(Supplement 1):111-24. https://doi.org/10.2337/dc21-S009.

28. Husain M, Consoli A, De Remigis A, Meyer AS, Rasmussen S, Bain S. Semaglutide reduced cardiovascular events regardless of metformin use: a post hoc exploratory subgroup analysis of SUSTAIN 6 AND PIONEER 6. J Am Coll Cardiol. 2021;77(18):Suppl 1:1604-4. 
29. UKPDS Group. Effect of intensive blood-glucose control with metformin on complications in overweight patients with type 2 diabetes (UKPDS 34). Lancet. 1998 Sep 12;352(9131):854 - 65.

30. Lamanna C, Monami M, Marchionni N, et al. Effect of metformin on cardiovascular events and mortality: a metaanalysis of randomized clinical trials. Diabetes Obes Metab. 2011;13:221-8. https://doi.org/10.1111/j.14631326.2010.01349.x.

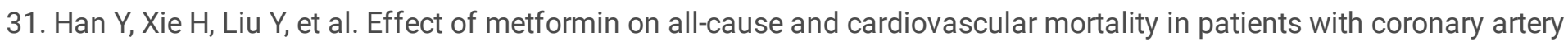
diseases: a systematic review and an updated meta-analysis. Cardiovasc Diabetol. 2019;18:96. https://doi.org/10.1186/s12933-019-0900-7. 36.

32. Griffin SJ, Leaver JK, Irving GJ. Impact of metformin on cardiovascular disease: a meta-analysis of randomised trials among people with type 2 diabetes. Diabetología. 2017 Sep;60(9):1620-9. https://doi.org/10.1007/s00125-017-43379.

33. Hinnen D. GLucagon-Like Peptide 1 Receptor Agonists for type 2 diabetes. Diabetes Spectr. 2017 Aug;30(3):202-10. https://doi.org/10.2337/ds16-0026.

34. Nauck MA, Meier JJ, Cavender MA, Abd El Aziz M, Drucker DJ. Cardiovascular Actions and Clinical outcomes with Glucagon-Like Peptide-1 Receptor Agonists and Dipeptidyl Peptidase-4 Inhibitors.Circulation.2017;136:849-870. https://doi.org/10.1161/CIRCULATIONAHA.117.028136.

35. Zoungas S, Arima H, Gerstein HC, Holman RR, Woodward M, Reaven P, et al. Effects of intensive glucose control on microvascular outcomes in patients with type 2 diabetes: a meta-analysis of individual participant data from randomised controlled trials. Lancet Diabetes Endocrinol. 2017;5:431-7. https://doi.org/10.1016/S22138587(17)30104-3.

36. Holman RR, Paul SK, Bethel MA, Matthews DR. Neil HA 10-year follow-up of intensive glucose control in type 2 diabetes. N Engl J Med. 2008 Oct 9; 359(15):1577-89. https://doi.org/10.1056/NEJMoa0806470.

37. ACCORD Study Group Nine-. Year effects of 3.7 years of intensive glycemic control on cardiovascular outcomes. Diabetes Care. 2016;39:701-8. https://doi.org/10.2337/dc15-2283.

38. Macisaac RJ, Jerums G. Intensive glucose control and cardiovascular outcomes in type 2 diabetes. Heart Lung Circ. 2011 Oct;20(10):647-54. https://doi.org/10.1016/j.hlc.2010.07.013.

39. Bahne E, Sun EWL, Young R, et al. Metformin-induced glucagon-like peptide-1 secretion contributes to the action of metformin in type 2 diabetes. JCI Insight. 2018 Dec 6;3(23):e93936. https://doi.org/10.1172/jci.insight.93936.JCI.

40. Giugliano D, Maiorino M, Bellastella G, Longo M, Chiodini P, Esposito K. GLP-1 receptor agonists for prevention of cardiorenal outcomes in type 2 diabetes: An updated meta-analysis including de REWIND and PIONEER 6 trials. Diabetes Obes Metab. 2019;21:2576-80. https://doi.org/10.1111/dom.13847.

\section{Figures}




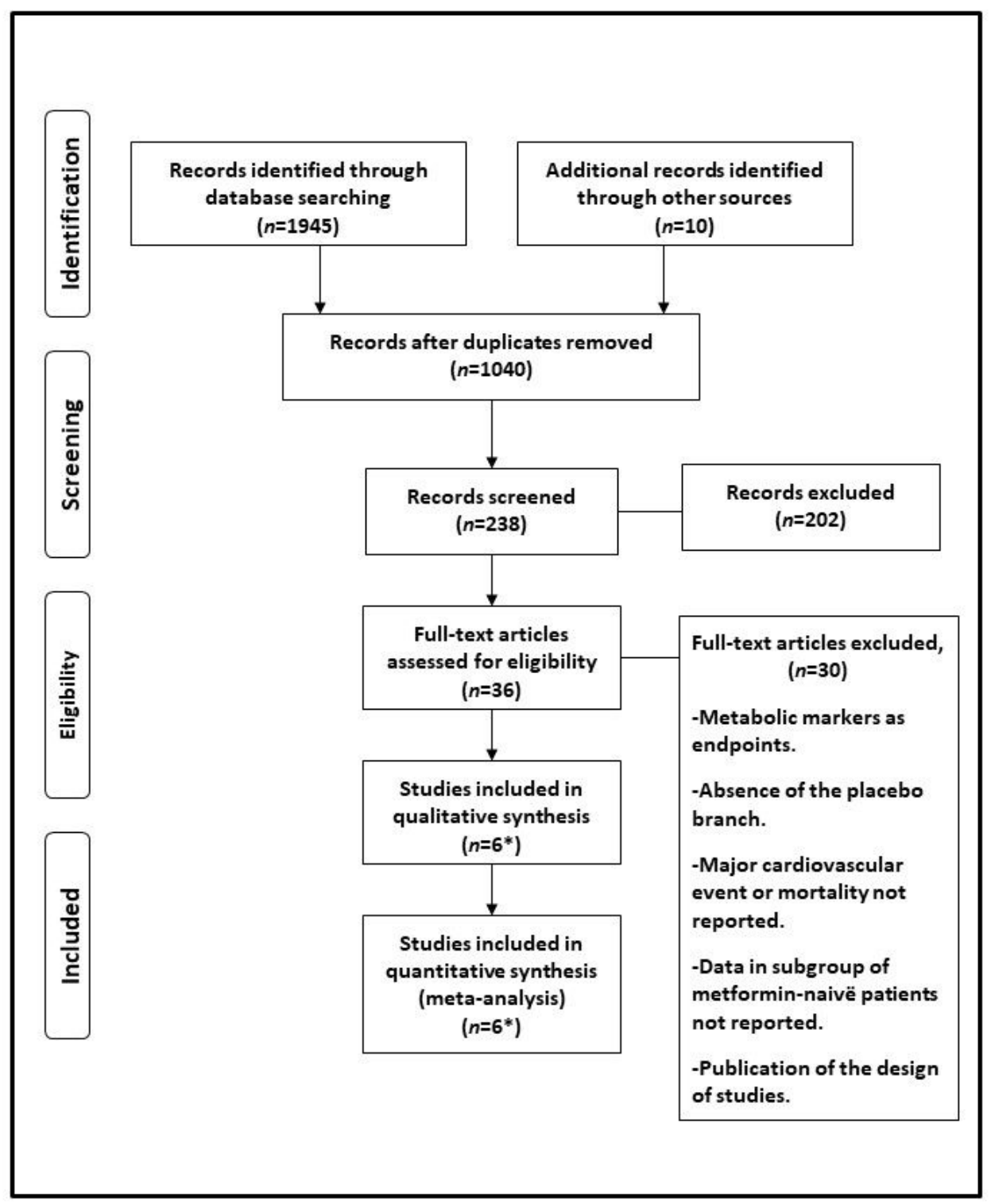

Figure 1

Six eligible trials ( 5 studies of subcutaneous GLP-1RAs and 1 with oral GLP-1RAs), including 10419 patients, were identified and considered eligible for the analyses. A total of 5274 subjects were allocated to receive GLP-1RAs while 5145 subjects were allocated to the respective control arms. A flow diagram of the study's screening process has been shown in Figure 1. 


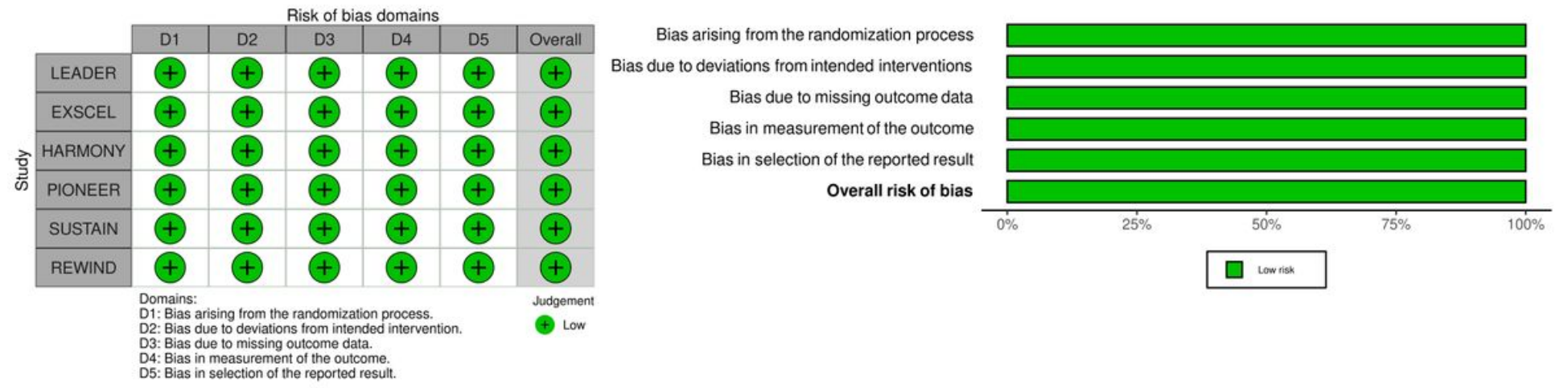

Figure 2

The total of studies evaluated were randomized clinical trials. Overall, the risk of bias was low in all the six studies. The quality of the studies evaluated can be seen in Figure 2.

\begin{tabular}{|c|c|c|c|c|c|c|}
\hline Study & $\log (H R)$ & SE Log(HR) & Hazard Ratio & HR & $95 \%-\mathrm{Cl}$ & Weight \\
\hline \multicolumn{7}{|l|}{ Event $=$ MACE } \\
\hline LEADER & -0.24 & 0.1061 & & 0.79 & {$[0.64 ; 0.97]$} & $12.1 \%$ \\
\hline EXSCEL & -0.17 & 0.1022 & & 0.84 & {$[0.69 ; 1.03]$} & $13.0 \%$ \\
\hline HARMONY & -0.24 & 0.1220 & & 0.79 & {$[0.62 ; 1.00]$} & $9.1 \%$ \\
\hline PIONEER+SUSTAIN & -0.13 & 0.1576 & & 0.88 & {$[0.65 ; 1.20]$} & $5.5 \%$ \\
\hline REWIND & -0.07 & 0.0655 & & 0.93 & {$[0.82 ; 1.06]$} & $31.7 \%$ \\
\hline Fixed effect model & & & & 0.87 & {$[0.80 ; 0.94]$} & $71.4 \%$ \\
\hline \multicolumn{7}{|c|}{ Heterogeneity: $I^{2}=0 \%, \tau^{2}=0, p=0.63$} \\
\hline \multicolumn{7}{|c|}{ Event $=$ All-cause mortality } \\
\hline LEADER & -0.09 & 0.1172 & — & 0.91 & {$[0.72 ; 1.15]$} & $9.9 \%$ \\
\hline PIONEER+SUSTAIN & -0.29 & 0.2316 & & 0.75 & {$[0.48 ; 1.18]$} & $2.5 \%$ \\
\hline REWIND & -0.19 & 0.1272 & & 0.83 & {$[0.65 ; 1.06]$} & $8.4 \%$ \\
\hline Fixed effect model & & & & 0.86 & {$[0.73 ; 1.00]$} & $20.8 \%$ \\
\hline \multicolumn{7}{|c|}{ Heterogeneity: $I^{2}=0 \%, \tau^{2}=0, p=0.72$} \\
\hline \multicolumn{7}{|c|}{ Event $=$ Cardiovascular death } \\
\hline LEADER & -0.24 & 0.1519 & & 0.79 & {$[0.59 ; 1.06]$} & $5.9 \%$ \\
\hline PIONEER+SUSTAIN & -0.12 & 0.2736 & & 0.89 & {$[0.52 ; 1.52]$} & $1.8 \%$ \\
\hline \multirow{2}{*}{\multicolumn{7}{|c|}{ Heterogeneity: $I^{2}=0 \%, \tau^{2}=0, p=0.70$}} \\
\hline & & & & & & \\
\hline \multicolumn{4}{|c|}{ Fixed effect model } & 0.86 & {$[0.80 ; 0.92]$} & $100.0 \%$ \\
\hline \multirow{2}{*}{\multicolumn{2}{|c|}{ Heterogeneity: $I^{2}=0 \%, \tau^{2}=0, p=0.93$}} & 0 & 1 & & & \\
\hline & & & Best Poor & & & \\
\hline
\end{tabular}

\section{Figure 3}

The present meta-analysis revealed that GLP-1RAs drugs were associated with a significant reduction in MACE (HR: 0.87, $95 \% \mathrm{Cl}: 0.80-0.94 ; 12: 0 \%)$. The analysis of the secondary endpoint showed that GLP-1RAs were associated with a nonsignificant reduction in all-cause mortality (HR: 0.86, 95\% Cl: 0.73-1.00; I2: 0\%) and cardiovascular mortality (HR: 0.81, 95\% 
Cl: $0.63-1.05 ;$ I2: $0 \%)$ The graphic representation of the effect of GLP-1RAs on primary and secondary end-point can be seen in Figure 3.

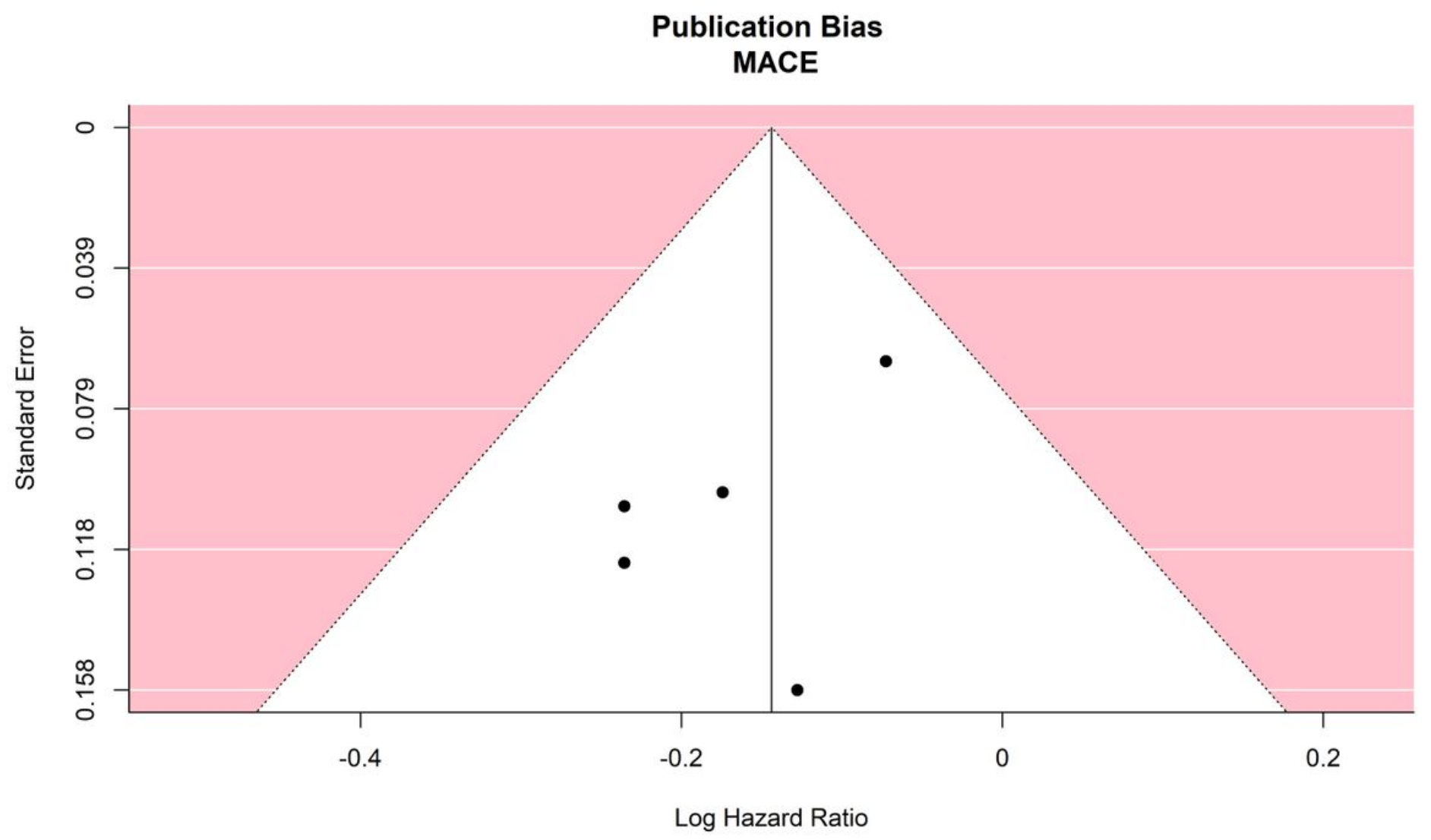

Figure 4

The funnel plot in Figure 4 and analytical evaluation do not suggest publication bias (Egger's asymmetry test, $p=0.19$ ).

Study

Omitting LEADER

Omitting EXSCEL

Omitting HARMONY

Omitting PIONEER+SUSTAIN

Omitting REWIND

Fixed effect model
Hazard Ratio

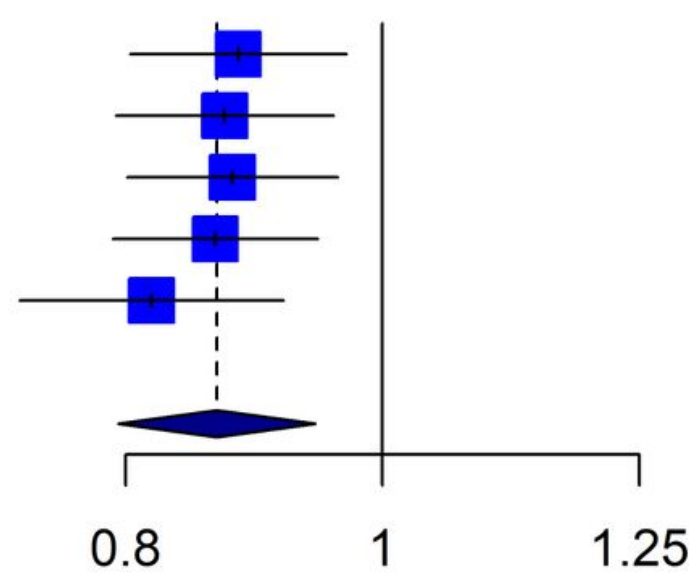

HR

$95 \%-\mathrm{Cl}$

$0.88 \quad[0.80 ; 0.97]$

$0.87 \quad[0.79 ; 0.96]$

$0.88 \quad[0.80 ; 0.96]$

$0.86 \quad[0.79 ; 0.95]$

$0.82 \quad[0.73 ; 0.92]$

$0.87[0.80 ; 0.94]$

Figure 5

The sensitivity analysis showed the same directionality of results when studies were excluded one by one (Figure 5) 